\title{
Long Wavelength TCF-Based Fluorescent Probe for the Detection of Alkaline Phosphatase in Live Cells
}

\author{
Lauren Gwynne ${ }^{1}$, Adam C. Sedgwick ${ }^{2}$, Jordan E. Gardiner ${ }^{1}$, George T. Williams ${ }^{1}$, \\ Gyoungmi Kim ${ }^{3}$, John P. Lowe ${ }^{1}$, Jean-Yves Maillard ${ }^{4}$, A. Toby A. Jenkins ${ }^{1 *}$, \\ Steven D. Bull ${ }^{1 *}$, Jonathan L. Sessler ${ }^{2 *}$, Juyoung Yoon ${ }^{3 *}$ and Tony D. James ${ }^{1 *}$ \\ ${ }^{1}$ Department of Chemistry, University of Bath, Bath, United Kingdom, ${ }^{2}$ Department of Chemistry, University of Texas at \\ Austin, Austin, TX, United States, ${ }^{3}$ Department of Chemistry and Nano Science, Ewha Womans University, Seoul, \\ South Korea, ${ }^{4}$ Cardiff School of Pharmacy and Pharmaceutical Sciences, Cardiff University, Cardiff, United Kingdom
}

OPEN ACCESS

Edited by:

Leyong Wang

Nanjing University, China

Reviewed by:

Ruibing Wang,

University of Macau, China

Huaqiang Zeng,

Institute of Bioengineering and Nanotechnology (A*STAR), Singapore

*Correspondence:

A. Toby A. Jenkins a.ta.jenkins@bath.ac.uk

Steven D. Bull

s.d.bull@bath.ac.uk

Jonathan L. Sessler

sessler@cm.utexas.edu Juyoung Yoon jyoon@ewha.ac.k

Tony D. James

t.d.james@bath.ac.uk

Specialty section:

This article was submitted to

Supramolecular Chemistry,

a section of the journal

Frontiers in Chemistry

Received: 02 January 2019 Accepted: 01 April 2019 Published: 30 April 2019

Citation:

Gwynne L, Sedgwick AC Gardiner JE, Williams GT, Kim G, Lowe JP, Maillard J-Y, Jenkins ATA,

Bull SD, Sessler JL, Yoon J and James TD (2019) Long Wavelength TCF-Based Fluorescent Probe for the

Detection of Alkaline Phosphatase in Live Cells. Front. Chem. 7:255 doi: 10.3389/fchem.2019.00255
A long wavelength TCF-based fluorescent probe (TCF-ALP) was developed for the detection of alkaline phosphatase (ALP). ALP-mediated hydrolysis of the phosphate group of TCF-ALP resulted in a significant fluorescence "turn on" (58-fold), which was accompanied by a colorimetric response from yellow to purple. TCF-ALP was cell-permeable, which allowed it to be used to image ALP in HeLa cells. Upon addition of bone morphogenic protein 2, TCF-ALP proved capable of imaging endogenously stimulated ALP in myogenic murine C2C12 cells. Overall, TCF-ALP offers promise as an effective fluorescent/colorimetric probe for evaluating phosphatase activity in clinical assays or live cell systems.

Keywords: reaction-based fluorescent probe, alkaline phosphatase, cell imaging, fluorescence, colorimetric

\section{INTRODUCTION}

Alkaline phosphatase (ALP) is an ubiquitous enzyme found in the majority of human tissues, where it catalyses the dephosphorylation of various substrates such as nucleic acids, proteins, and other small molecules (Coleman, 1992; Millán, 2006). ALP also plays an important role in signal transduction and regulation of intracellular processes (cell growth, apoptosis, and signal transduction pathways) (Julien et al., 2011). Abnormal levels of ALP in serum are an indicator of several diseases including bone disease (Garnero and Delmas, 1993), liver dysfunction (Rosen et al., 2016), breast and prostatic cancer (Ritzke et al., 1998; Wymenga et al., 2001), and diabetes (Tibi et al., 1988). As a result, ALP is regarded as a key biomarker in medical diagnosis (Coleman, 1992; Ooi et al., 2007). Therefore, it is important to develop a fast, reliable, and selective detection system for monitoring ALP activity that is amenable to clinical diagnostics.

There have been numerous approaches to determine ALP levels, including colorimetric (Yang et al., 2016; Hu et al., 2017), chemiluminescent (Jiang and Wang, 2012), electrochemical (Zhang L. et al., 2015), surface-enhanced Raman methods (Ruan et al., 2006), and fluorescence (Cao et al., 2016; Fan et al., 2016). Our group has been particularly interested in the development of fluorescent probes for the detection of biologically relevant analytes (Sedgwick et al., 2017a,b, 2018a,b; Wu et al., 2017; Zhang et al., 2019). Fluorescence has many advantages over other methods owing to its simplicity and high sensitivity/selectivity, providing rapid, non-invasive, real-time detection ( $\mathrm{Wu}$ et al., 2017). Whilst there have been many fluorophores developed for assaying ALP activity such as organic dyes (Zhang H. et al., 2015; Zhao et al., 2017), conjugated polymers (Li et al., 2014), inorganic semiconductor dots (Qian et al., 2015), and noble metal clusters (Sun et al., 2014), most require 
high probe concentrations and crucially rely on short wavelength emission, thus limiting their applicability in biological systems. Therefore, ALP probes that operate at long wavelengths are required to allow for deeper tissue penetration and to avoid cell-based autofluorescence (Liu et al., 2017; Tan et al., 2017; Zhang et al., 2017).

\section{RESULTS AND DISCUSSION}

\section{Chemistry}

Here we report a TCF-based fluorescent probe that allows for the detection of ALP and/or acid phosphatase (ACP). As shown in Scheme 1, this probe (TCF-ALP) is based on the conjugation of 2-dicyanomethylene-3-cyano-4,5,5-trimethyl2,5-dihydrofuran (TCF) to an electron-donating phenol moiety, a phosphorylated phenol; this affords an internal charge transfer (ICT) donor- $\pi$-acceptor (D- $\pi$-A) system whose fluorescence properties vary dramatically following ALP-mediated phosphate group cleavage (Gopalan et al., 2004; Liao et al., 2006; Bouffard et al., 2008; Lord et al., 2008; Jin et al., 2010; Sedgwick et al., 2017b; Teng et al., 2018). TCF-ALP was synthesized in four steps with an overall yield of 27\% (Scheme 2). In brief, 3-hydroxy-3-methyl-2-butanone, malononitrile, and $\mathrm{NaOEt}$ were heated at reflux in EtOH for $1 \mathrm{~h}$ and then cooled. The resultant precipitate TCF (1) was then added to a mixture of piperidine (cat.) and 4-hydroxybenzaldehyde in $\mathrm{EtOH}$, which was subsequently heated to $100^{\circ} \mathrm{C}$ by microwave irradiation to afford intermediate 2 (TCF-OH). Intermediate 2 was then treated with diethylchlorophosphate, DMAP (cat.) and $\mathrm{NEt}_{3}$ in THF to give the phosphonate ester 3. Hydrolysis using trimethylsilyl iodide in dichloromethane (DCM) afforded TCF-ALP as a crystalline solid (After trituration with $\mathrm{Et}_{2} \mathrm{O}$ ).

\section{Spectroscopic Studies of TCF-ALP}

UV-Vis and fluorescence spectroscopic titrations of TCF-ALP were performed in $50 \mathrm{mM}$ Tris- $\mathrm{HCl}$ buffer in the absence and presence of ALP from porcine kidney. In the absence of ALP, TCF-ALP was found to have no UV absorption features above $\sim 550 \mathrm{~nm}$; however, upon addition of ALP a bathochromic shift in the UV absorption maximum was observed (from 440 to $580 \mathrm{~nm}$ ), which was accompanied by a change in color from yellow to purple (Figure S1). ALP-mediated hydrolysis of TCF-
ALP to form the highly fluorescent phenol (2), was confirmed by ${ }^{31} \mathrm{P}$ NMR studies and HRMS (see Figures S1-S4). The effect of $\mathrm{pH}$ on the rate of ALP mediated hydrolysis of TCF-ALP was evaluated. It was found that incubation with $0.8 \mathrm{U} / \mathrm{mL}$ of ALP at $\mathrm{pH} 9.2$ resulted in the largest fluorescence response (Figure S5). Consequently, all in vitro experiments to determine ALP activity were carried out in $50 \mathrm{mM}$ Tris- $\mathrm{HCl}$ buffer at $\mathrm{pH}$ 9.2.

The kinetics of ALP toward TCF-ALP were determined via fluorescence spectroscopy (Figures S6, S7), with the resultant fluorescence data analyzed using the Michaelis-Menten equation (Figure S8). This revealed a $\mathrm{K}_{\mathrm{m}}$ of $35.81 \pm 2.63 \mu \mathrm{M}$ and a $\mathrm{V}_{\max }$ of $3029 \pm 157.3 \mathrm{~min}^{-1}$ for hydrolysis of TCF-ALP by ALP at pH 9.2 (see Supplementary Material for details). TCF-ALP was then incubated with various concentrations of ALP (0.0$0.2 \mathrm{U} / \mathrm{mL}$ ) for $15 \mathrm{~min}$ to evaluate its ability to monitor ALP activity. As shown in Figure 1, a significant fluorescence response was observed in the presence of ALP (58-fold) with a limit of detection (LOD) calculated as $0.12 \mathrm{mU} / \mathrm{mL}$ (Figure S9). This sensitivity is comparable to other fluorescent probes found in the literature (Table S3). Although serum alkaline phosphatase levels vary with age in normal individuals (Kattwinkel et al., 1973), it is widely accepted that serum ALP levels in healthy adults lies between 39 and $117 \mathrm{U} / \mathrm{mL}$ (Saif et al., 2005; Sahran et al., 2018). This suggests that TCF-ALP is capable of detecting ALP in human serum, and therefore could be used in clinical assays.

Inhibition studies were carried out in the presence of sodium orthovanadate $\left(\mathrm{Na}_{3} \mathrm{VO}_{4}\right)$, which is known to be a strong inhibitor of ALP activity. Addition of $\mathrm{Na}_{3} \mathrm{VO}_{4}$ resulted in a decrease in the fluorescence response in the TCF-ALP hydrolysis assay (see Figure S10) (Swarup et al., 1982). These inhibition studies enabled an $\mathrm{IC}_{50}$ of $6.23 \mu \mathrm{M}$ to be calculated (Figure S11), which is similar in value to other ALP substrates that have been reported in the literature (Zhang H. et al., 2015; Tan et al., 2017).

The selectivity of TCF-ALP toward other biologically relevant enzymes (at their optimal $\mathrm{pH}$ values) was then determined (Figure 2 and Figure S12), with TCF-ALP displaying high substrate selectivity for ALP over other common hydrolytic enzymes (e.g., trypsin, porcine liver esterase) or non-specific binding proteins [e.g., bovine serum albumin (BSA)]. Interestingly, TCF-ALP produced a fluorescence response when treated with ACP. The detection of this enzyme is of significance since it is a tumor biomarker for metastatic prostate cancer (Makarov et al., 2009). Normal levels of ACP
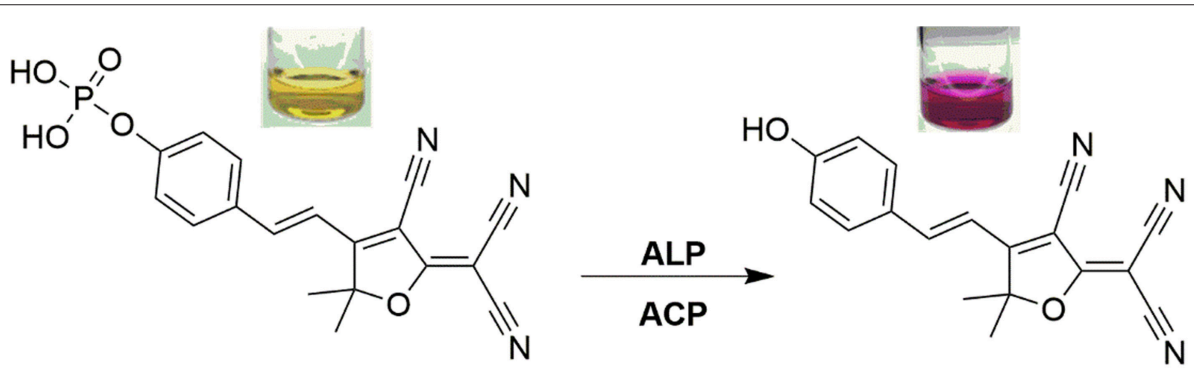

TCF-ALP

SCHEME 1 | A TCF-based fluorescence probe (TCF-ALP) for the detection of alkaline phosphatase. 
<smiles>CC(=O)C(C)(C)O</smiles>

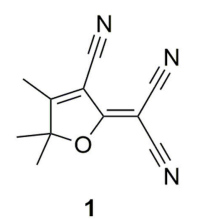

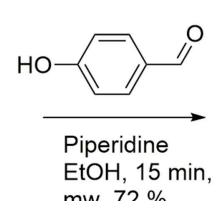

$\mathrm{mw}, 72 \%$<smiles>CC1(C)OC(=C(C#N)C#N)C(C#N)=C1/C=C/c1ccc(O)cc1</smiles>

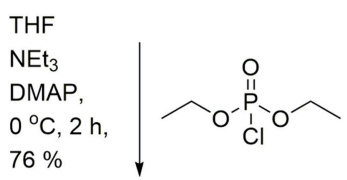<smiles>CC1(C)OC(=C(C#N)C#N)C(C#N)=C1/C=C/c1ccc(OP(=O)(O)O)cc1</smiles>
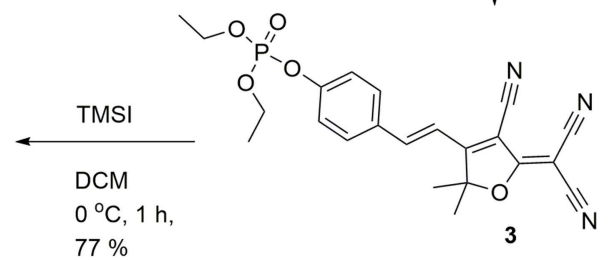

SCHEME 2 | Synthesis of TCF-ALP.

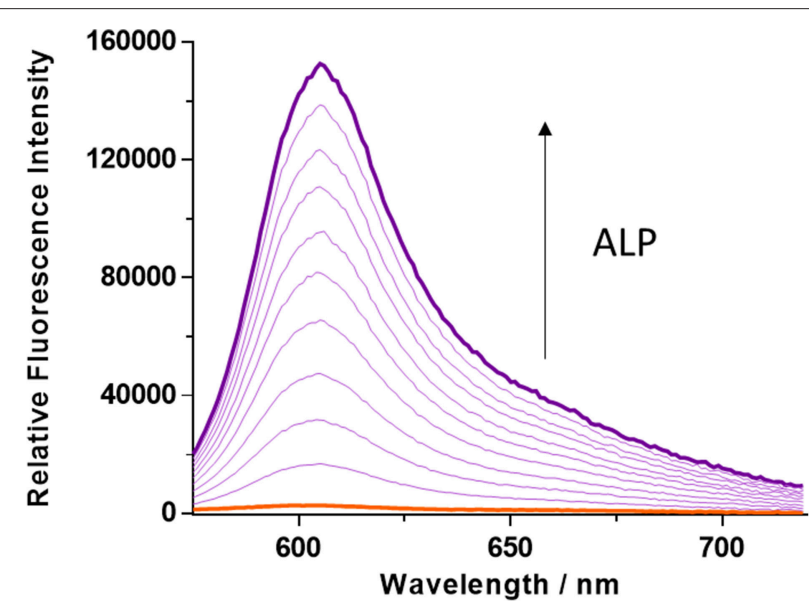

FIGURE 1 | Fluorescence spectra of TCF-ALP $(10 \mu \mathrm{M})$ produced via the addition of alkaline phosphatase (ALP; $0-0.2 \mathrm{U} / \mathrm{mL}$ ) in $50 \mathrm{mM}$ Tris- $\mathrm{HCl}$ buffer, $\mathrm{pH}=9.2$ at $25^{\circ} \mathrm{C} . \lambda_{\mathrm{ex}}=542$ (bandwidth 15) $\mathrm{nm}$. All measurements were made $15 \mathrm{~min}$ after the addition of ALP.

in serum range from 3.0 to $4.7 \mathrm{U} / \mathrm{mL}$, and elevated ACP levels can be indicative of a variety of other diseases (Bull et al., 2002). Furthermore, TCF-ALP proved capable of detecting ACP (25fold fluorescence enhancement) and ALP (38-fold enhancement) at a physiological $\mathrm{pH}$ of 7.1 (Figures S13, S14). Kinetic determination of ALP and ACP toward TCF-ALP at $\mathrm{pH} 7.1$ was conducted, and the resultant $\mathrm{K}_{\mathrm{m}}$ and $\mathrm{V}_{\max }$ were compared (see Supplementary Material 3.1 and Figures S15-S18). It was found that ALP has a smaller $\mathrm{K}_{\mathrm{m}}$ value in comparison to ACP $(0.38 \pm 0.042 \mu \mathrm{M}$ and $99.22 \pm 13.16 \mu \mathrm{M}$, respectively $)$ and a lower $V_{\max }\left(208 \pm 3.81 \mathrm{~min}^{-1}\right.$ and $1962 \pm 223.6 \mathrm{~min}^{-1}$, respectively). Hence, ALP has higher affinity toward TCF-ALP compared to ACP, thus TCF-ALP is more selective toward ALP at physiological $\mathrm{pH}$.

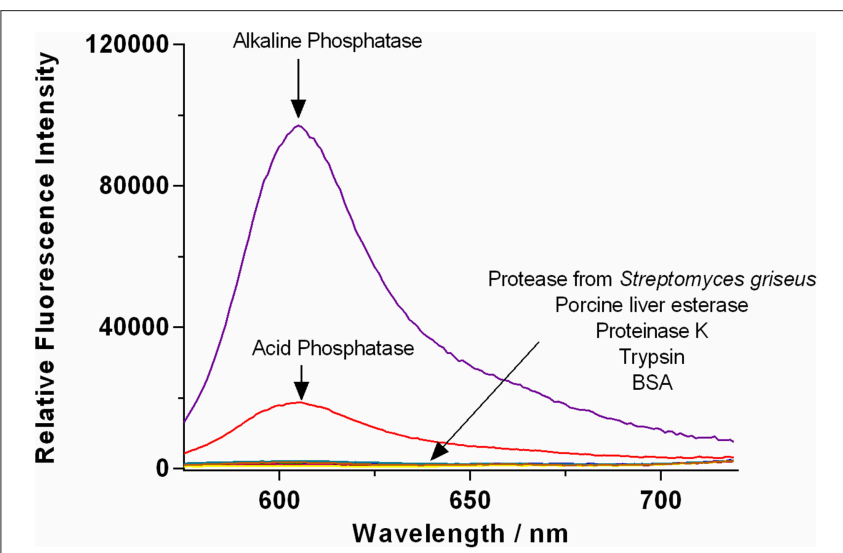

FIGURE 2 | Fluorescence spectra of TCF-ALP $(10 \mu \mathrm{M})$ recorded in the presence of trypsin $(0.8 \mathrm{BAEE} \mathrm{U} / \mathrm{mL})$, porcine liver esterase, protease from Streptomyces griseus, proteinase $\mathrm{K}$, bovine serum albumin $(0.1 \mathrm{mg} / \mathrm{mL})$, acid phosphatase $(50 \mathrm{mM}$ Tris- $\mathrm{HCl}, \mathrm{pH}=5.0)$, and alkaline phosphatase $(50 \mathrm{mM}$ Tris- $\mathrm{HCl}, \mathrm{pH}=9.2$ ). All enzymes were standardized to $0.8 \mathrm{U} / \mathrm{mL}$ in Tris- $\mathrm{HCl}$ buffer $\mathrm{pH} 7.1$ unless otherwise stated. $\lambda_{\mathrm{ex}}=542$ (bandwidth 15$) \mathrm{nm} / \lambda_{\mathrm{em}}=$ $606 \mathrm{~nm}$. Fluorescence measurements were made $30 \mathrm{~min}$ after adding the enzyme in question.

According to current standards, determination of ALP and $\mathrm{ACP}$ is undertaken at the phosphatase's optimum $\mathrm{pH}$. For example, the Centers for Disease Control and Prevention (CDC) procedure for ALP determination is carried out in 2-amino-2methyl-1-propanol (AMP) buffer at pH 10.3 [Centers For Disease Control Prevention (CDC), 2012]. This is in accordance with other literature sources (Di Lorenzo et al., 1991; Radio et al., 2006; Pandurangan and Kim, 2015; Guo et al., 2018). Likewise, ACP determination is carried out at $\mathrm{pH} 4-6$ ( $\mathrm{Li}$ et al., 1984; Boivin and Galand, 1986; Myers and Widlanski, 1993). Following these observations, further studies were conducted to determine selectivity at pH 5.0 and 9.2 (Figures S19-S22). Results showed 
that TCF-ALP acts selectivity toward ACP at acidic $\mathrm{pH}$, and ALP at alkaline pH. Therefore, TCF-ALP can be used to selectively detect ALP/ACP in clinical assays, or live cell systems (provided the buffer solution is optimal for the phosphatase under study).

\section{Imaging of ALP in Living Cells}

Prior to exploring whether TCF-ALP could be used to image ALP activity levels in live cells, the cytotoxicity of TCF-ALP was assessed using a MTT assay (Figure S23). Negligible cell toxicity was observed for TCF-ALP concentrations between 0 and $5 \mu \mathrm{M}$, and cell viability was only slightly reduced (91\%) when incubated with $10 \mu \mathrm{M}$ TCF-ALP, indicating good biocompatibility.

TCF-ALP proved cell permeable to HeLa cells that express ALP and provided a clear "turn on" response (Figure 3). In contrast, pre-treatment of $\mathrm{HeLa}$ cells with $\mathrm{Na}_{3} \mathrm{VO}_{4}(5 \mathrm{mM})$ prior to incubation with TCF-ALP resulted in minimal "turn on." This was taken as evidence that the increase in TCF-ALP fluorescence levels seen for HeLa cells in the absence of $\mathrm{Na}_{3} \mathrm{VO}_{4}$ is due to ALP activity. We thus conclude TCF-ALP is a probe that allows for the selective cellular imaging of ALP activity.

Bone morphogenetic protein 2 (BMP-2) is capable of inducing osteoblast differentiation into a variety of cell types (Guo et al., 2014; Wang et al., 2015) via pathways that result in increased ALP mRNA expression, leading to increased ALP activity (Kim et al., 2004). Treatment of myogenic murine C2C12 cells with TCFALP resulted in a low fluorescence intensity (low ALP levels) being observed (Figure 4); however, pre-treatment of these cells with BMP-2 (300 ng/mL, 3 days) resulted in a significant increase in TCF-ALP-derived fluorescence intensity (high ALP levels). Once again, pre-incubation with $\mathrm{Na}_{3} \mathrm{VO}_{4}(5 \mathrm{mM})$ led to no fluorescence response being observed in the cells treated with
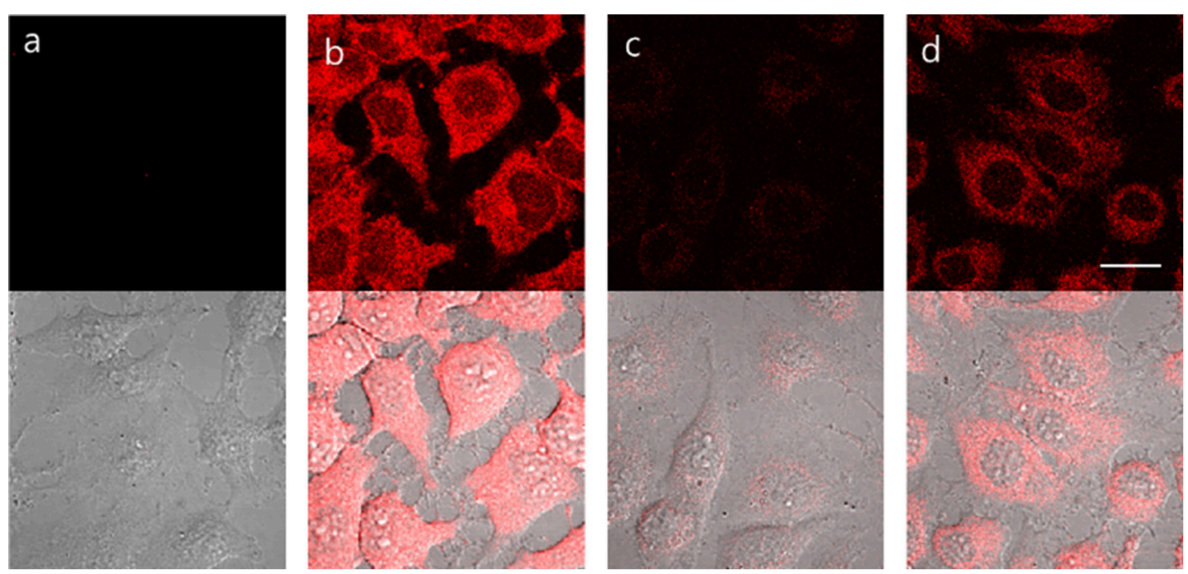

FIGURE 3 | HeLa cells incubated under the following conditions: (a) No treatment. (b) TCF-ALP (10 $\mu \mathrm{M}, 30 \mathrm{~min})$. (c) Pre-treated with $\mathrm{Na}_{3} \mathrm{VO}_{4}(5 \mathrm{mM}, 30 \mathrm{~min})$, followed by the addition of TCF-ALP $(10 \mu \mathrm{M}, 30 \mathrm{~min})$. (d) Pretreated with $\mathrm{Na}_{3} \mathrm{VO}_{4}(0.5 \mathrm{mM}, 30 \mathrm{~min})$ and TCF-ALP $(10 \mu \mathrm{M}, 30 \mathrm{~min})$. Cells were washed with DPBS before their fluorescence images were acquired using a confocal microscope. Top half: fluorescence images, bottom half: fluorescence images merged with its corresponding DIC image. Ex. $559 \mathrm{~nm} / \mathrm{em} .575-675 \mathrm{~nm}$. Scale bar: $20 \mu \mathrm{m}$. DIC, differential interference contrast.
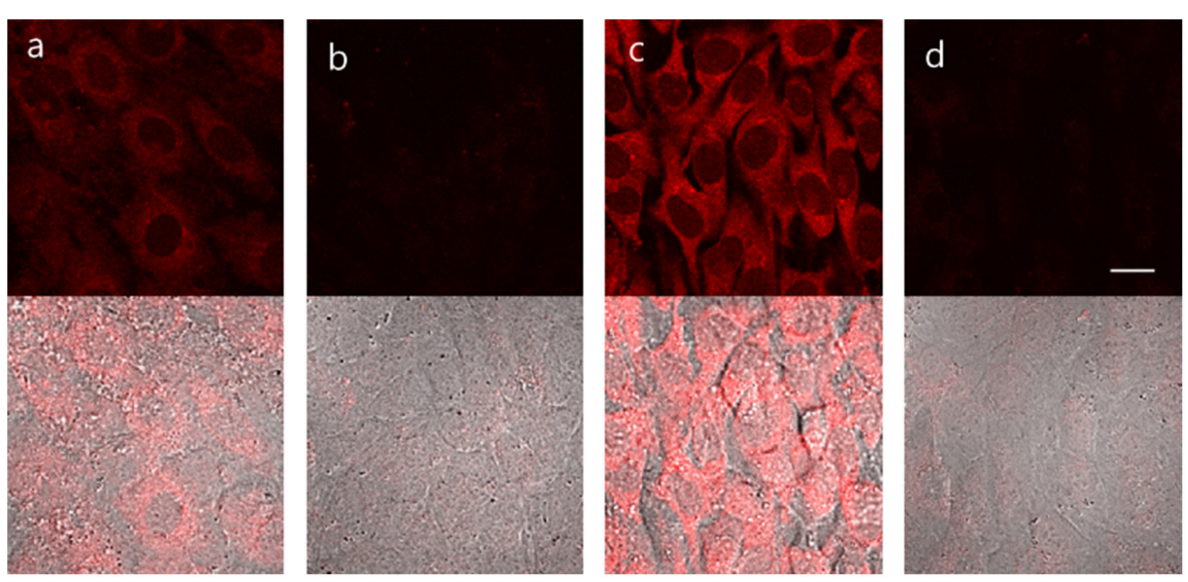

FIGURE 4 | TCF-ALP in C2C12 cells. C2C12 cells were treated with $300 \mathrm{ng} / \mathrm{mL}$ BMP-2 for 3 days and then pretreated with $5 \mathrm{mM}$ levamisole for 30 min and stained with $10 \mu \mathrm{M}$ TCF-ALP for $30 \mathrm{~min}$. After washing with DPBS, fluorescence images were acquired by confocal microscopy. (a) only TCF-ALP, (b) levamisole + TCF-ALP, (c) BMP-2 + TCF-ALP (d) BMP-2 + levamisole + TCF-ALP. Top: fluorescence images, bottom: merged with DIC image. Ex. 559 nm/em. 575-675 nm. Scale bar: $20 \mu \mathrm{m}$. DIC, differential interference contrast. 
TCF-ALP (with or without BMP-2). This provided support for the notion that TCF-ALP is capable of imaging endogenous ALP activity induced by BMP-2.

\section{CONCLUSIONS}

In summary, a long wavelength TCF-based fluorescent probe (TCF-ALP) has been prepared with the goal of detecting ALP activity. ALP Hydrolysis of the phosphate group of TCF-ALP resulted in a significant "turn on" fluorescence response (58-fold) within $15 \mathrm{~min}$. These spectroscopic changes were accompanied by a colorimetric change from yellow to purple. This enables TCF-ALP to be used as a simple assay for the evaluation of ALP activity. Further analysis revealed that TCF-ALP could also be used as a probe for detecting ACP activity. TCF-ALP was shown to be cell permeable, enabling its use as a fluorescent probe for monitoring ALP levels in HeLa cells. TCF-ALP also proved capable of imaging endogenously stimulated ALP produced in myogenic murine $\mathrm{C} 2 \mathrm{C} 12$ cells through the addition of bone morphogenetic protein 2. We thus suggest that TCF-ALP offers promise as a tool for measuring ALP and ACP activity levels in clinical assays or in live cell systems.

\section{AUTHOR CONTRIBUTIONS}

LG and AS carried out synthetic and spectroscopic experiments and co-wrote the manuscript with TJ and JS. JG and GW carried out background experiments. GK carried out

\section{REFERENCES}

Boivin, P., and Galand, C. (1986). The human red cell acid phosphatase is a phosphotyrosine protein phosphatase which dephosphorylates the membrane protein band 3. Biochem. Biophys. Res. Commun. 134, 557-564. doi: 10.1016/S0006-291X(86)80456-9

Bouffard, J., Kim, Y., Swager, T. M., Weissleder, R., and Hilderbrand, S. A. (2008). A highly selective fluorescent probe for thiol bioimaging. Org. Lett. 10, 37-40. doi: 10.1021/ol702539v

Bull, H., Murray, P. G., Thomas, D., Fraser, A. M., and Nelson, P. N. (2002). Acid phosphatases. J. Clin. Pathol. Mol. Pathol. 55, 65-72. doi: 10.1136/mp.55.2.65

Cao, F.-Y., Long, Y., Wang, S.-B., Li, B., Fan, J.-X., Zeng, X., et al. (2016). Fluorescence light-up aie probe for monitoring cellular alkaline phosphatase activity and detecting osteogenic differentiation. J. Mater. Chem. B 4, 4534-4541. doi: 10.1039/C6TB00828C

Centers For Disease Control and Prevention (CDC) (2012). Alkaline Phosphatase (ALP) in Refigerated Serum: NHANES 2011-2012. Available online at: https:// wwwn.cdc.gov/nchs/data/nhanes/2011-2012/labmethods/biopro_g_met_ alkaline_phosphatase.pdf (accessed January 29, 2019).

Coleman, J. E. (1992). Structure and mechanism of alkaline phosphatase. Annu. Rev. Biophys. Biomol. Struct. 21, 441-483. doi: 10.1146/annurev.bb.21.060192.002301

Di Lorenzo, D., Albertini, A., and Zava, D. (1991). Progestin regulation of alkaline phosphatase in the human breast cancer cell line T47D. Cancer Res. 51, 4470-4475.

Fan, C., Luo, S., and Qi, H. (2016). A ratiometric fluorescent probe for alkaline phosphatase via regulation of excited-state intramolecular proton transfer. Luminescence 31, 423-427. doi: 10.1002/bio.2977

Garnero, P., and Delmas, P. D. (1993). Assessment of the serum levels of bone alkaline phosphatase with a new immunoradiometric assay in cellular imaging experiments. JL carried out the ${ }^{31} \mathrm{P}$ NMR titrations. J-YM and AJ are supervisors of LG and GW. SB, JY, JS, and TJ all conceived the idea and helped with the manuscript.

\section{FUNDING}

This work was supported in part by grant MR/N0137941/1 for the GW4 BIOMED DTP, awarded to the Universities of Bath, Bristol, Cardiff and Exeter from the Medical Research Council (MRC)/UKRI We would also like to thank the EPSRC (EP/R003939/1) and the University of Bath and Public Health England for funding. AS and JS thank The Robert A. Welch Foundation (F-0018).

\section{ACKNOWLEDGMENTS}

TJ wishes to thank the Royal Society for a Wolfson Research Merit Award. The EPSRC UK National Mass Spectrometry Facility at Swansea University is thanked for mass analyses.

\section{SUPPLEMENTARY MATERIAL}

The Supplementary Material for this article can be found online at: https://www.frontiersin.org/articles/10.3389/fchem. 2019.00255/full\#supplementary-material

patients with metabolic bone disease. J. Clin. Endocrinol. Metab. 77, 1046-1053.

Gopalan, P., Katz, H. E., Mcgee, D. J., Erben, C., Zielinski, T., Bousquet, D., et al. (2004). Star-shaped azo-based dipolar chromophores: design, synthesis, matrix compatibility, and electro-optic activity. J. Am. Chem. Soc. 126, 1741-1747. doi: $10.1021 / \mathrm{ja} 039768 \mathrm{k}$

Guo, F. J., Jiang, R., Xiong, Z., Xia, F., Li, M., Chen, L., et al. (2014). Irela constitutes a negative feedback loop with bmp2 and acts as a novel mediator in modulating osteogenic differentiation. Cell Death Dis. 5:e1239. doi: 10.1038/cddis.2014.194

Guo, J., Gao, M., Song, Y., Lin, L., Zhao, K., Tian, T., et al. (2018). An allostericprobe for detection of alkaline phosphatase activity and its application in immunoassay. Front. Chem. 6:618. doi: 10.3389/fchem.2018.00618

Hu, Q., Zhou, B., Dang, P., Li, L., Kong, J., and Zhang, X. (2017). Facile colorimetric assay of alkaline phosphatase activity using fe (ii)-phenanthroline reporter. Chim. Acta 950, 170-177. doi: 10.1016/j.aca.2016.11.012

Jiang, H., and Wang, X. (2012). Alkaline phosphatase-responsive anodic electrochemiluminescence of cdse nanoparticles. Anal. Chem. 84, 6986-6993. doi: 10.1021/ac300983t

Jin, Y., Tian, Y., Zhang, W., Jang, S. H., Jen, A. K. Y., and Meldrum, D. R. (2010) Tracking bacterial infection of macrophages using a novel red-emission ph sensor. Anal. Bioanal. Chem. 398, 1375-1384. doi: 10.1007/s00216-010-4060-6

Julien, S. G., Dubé, N., Hardy, S., and Tremblay, M. L. (2011). Inside the human cancer tyrosine phosphatome. Nat. Rev. Cancer 11,35-49. doi: 10.1038/nrc2980

Kattwinkel, J., Taussig, L. M., Statland, B. E., and Verter, J. I. (1973). The effects of age on alkaline phosphatase and other serologic liver function tests in normal subjects and patients with cystic fibrosis. J. Pediatr. 82, 234-242.

Kim, Y. J., Lee, M. H., Wozney, J. M., Cho, J. Y., and Ryoo, H. M. (2004). Bone morphogenetic protein-2-induced alkaline phosphatase expression is stimulated by dlx 5 and repressed by msx2. J. Biol. Chem. 279, 50773-80. doi: $10.1074 /$ jbc.M404145200 
Li, H. C., Chernoff, J., Chen, L. B., and Kirschonbaum, A. (1984). A phosphotyrosyl-protein phosphatase activity associated with acid phosphatase from human prostate gland. Eur. J. Biochem. 138, 45-51. doi: 10.1111/j.1432-1033.1984.tb07879.x

Li, Y., Li, Y., Wang, X., and Su, X. (2014). A label-free conjugated polymerbased fluorescence assay for the determination of adenosine triphosphate and alkaline phosphatase. N. J. Chem. 38, 4574-4579. doi: 10.1039/C4 NJ00935E

Liao, Y., Bhattacharjee, S., Firestone, K. A., Eichinger, B. E., Paranji, R., Anderson, C. A., et al. (2006). Antiparallel-aligned neutral-ground-state and zwitterionic chromophores as a nonlinear optical material. J. Am. Chem. Soc. 128, 6847-6853. doi: $10.1021 / \mathrm{ja} 057903 \mathrm{i}$

Liu, H. W., Hu, X. X., Zhu, L., Li, K., Rong, Q., Yuan, L., et al. (2017). In vivo imaging of alkaline phosphatase in tumor-bearing mouse model by a promising near-infrared fluorescent probe. Talanta 175, 421-426. doi: 10.1016/j.talanta.2017.04.081

Lord, S. J., Conley, N. R., Lee, H. L. D., Samuel, R., Liu, N., Twieg, R. J., et al. (2008). A photoactivatable push- pull fluorophore for single-molecule imaging in live cells. J. Am. Chem. Soc. 130, 9204-9205. doi: 10.1021/ja802883k

Makarov, D. V., Loeb, S., Getzenberg, R. H., and Partin, A. W. (2009). Biomarkers for prostate cancer. Ann. Rev. Med. 60, 139-151. doi: 10.1146/annurev.med.60.042307.110714

Millán, J. L. (2006). Alkaline phosphatases. Purinergic Signal. 2, 335-41. doi: $10.1002 / 3527608060$

Myers, J. K., and Widlanski, T. S. (1993). Mechanism-based inactivation of prostatic acid phosphatase. Science 262, 1451-1453. doi: $10.1126 /$ science. 8248785

Ooi, K., Shiraki, K., Morishita, Y., and Nobori, T. (2007). High-molecular intestinal alkaline phosphatase in chronic liver diseases. J. Clin. Lab. Anal. 21, 133-139. doi: $10.1002 /$ jcla. 20178

Pandurangan, M., and Kim, D. H. (2015). ZnO nanoparticles augment ALT, AST, ALP, and LDH expressions in C2C12 cells. Saudi. J. Biol. Sci. 22, 679-684. doi: 10.1016/j.sjbs.2015.03.013

Qian, Z., Chai, L., Tang, C., Huang, Y., Chen, J., and Feng, H. (2015). Carbon quantum dots-based recyclable real-time fluorescence assay for alkaline phosphatase with adenosine triphosphate as substrate. Anal. Chem. 87, 2966-2973. doi: 10.1021/ac504519b

Radio, N. M., Doctor, J. S., and Witt-Enderby, P. A. (2006). Melatonin enhances alkaline phosphatase activity in differentiating human adult mesenchymal stem cells grown in osteogenic medium via MT2 melatonin receptors and the MEK/ERK (1/2) signaling cascade. J. Pineal Res. 40, 332-342. doi: 10.1111/j.1600-079X.2006.00318.x

Ritzke, C., Stieber, P., Untch, M., Nagel, D., Eiermann, W., and Fateh-Moghadam, A. (1998). Alkaline phosphatase isoenzymes in detection and follow up of breast cancer metastases. Anticancer Res. 18, 1243-1249.

Rosen, E., Sabel, A. L., Brinton, J. T., Catanach, B., Gaudiani, J. L., and Mehler, P. S. (2016). Liver dysfunction in patients with severe anorexia nervosa. Int. J. Eat. Disord. 49, 151-158. doi: 10.1002/eat.22436

Ruan, C., Wang, W., and Gu, B. (2006). Detection of alkaline phosphatase using surface-enhanced raman spectroscopy. Anal. Chem. 78, 3379-3384. doi: $10.1021 /$ ac0522106

Sahran, Y., Sofian, A., and Saad, A. (2018). Pre-treatment serum lactate dehydrogenase (LDH) and serum alkaline phosphatase (ALP) as prognostic factors in patients with osteosarcoma. J Cancer. Prev. Curr. Res. 9, 58-63. doi: 10.15406/jcpcr.2018.09.00320

Saif, M. W., Alexander, D., and Wicox, C. M. (2005). Serum alkaline phosphatase level as a prognostic tool in colorectal cancer: a study of 105 patients. J. Appl. Res. 5, 88-95.

Sedgwick, A. C., Chapman, R. S. L., Gardiner, J. E., Peacock, L. R., Kim, G., Yoon, J., et al. (2017a). A bodipy based hydroxylamine sensor. Chem. Commun. 53, 10441-10443. doi: 10.1039/C7CC05872A

Sedgwick, A. C., Gardiner, J. E., Kim, G., Yevglevskis, M., Lloyd, M. D., Jenkins, A. T. A., et al. (2018a). Long-wavelength tcf-based fluorescence probes for the detection and intracellular imaging of biological thiols. Chem. Commun. 54, 4786-4789. doi: 10.1039/C8CC01661E

Sedgwick, A. C., Han, H. H., Gardiner, J. E., Bull, S. D., He, X. P., and James, T. D. (2017b). Long-wavelength fluorescent boronate probes for the detection and intracellular imaging of peroxynitrite. Chem. Commun. 53, 12822-12825. doi: 10.1039/C7CC07845E

Sedgwick, A. C., Han, H. H., Gardiner, J. E., Bull, S. D., He, X. P., and James, T. D. (2018b). The development of a novel and logic based fluorescence probe for the detection of peroxynitrite and gsh. Chem. Sci. 9, 3672-3676. doi: 10.1039/C8SC00733K

Sun, J., Yang, F., Zhao, D., and Yang, X. (2014). Highly sensitive real-time assay of inorganic pyrophosphatase activity based on the fluorescent gold nanoclusters. Anal. Chem. 86, 7883-7889. doi: 10.1021/ac501814u

Swarup, G., Cohen, S., and Garbers, D. L. (1982). Inhibition of membrane phosphotyrosyl-protein phosphatase activity by vanadate. Biochem. Biophys. Res. Commun. 107, 1104-1109. doi: 10.1016/0006-291X(82)9 0635-0

Tan, Y., Zhang, L., Man, K. H., Peltier, R., Chen, G., Zhang, H., et al. (2017). Reaction-based off-on near-infrared fluorescent probe for imaging alkaline phosphatase activity in living cells and mice. ACS Appl. Mater. Interfaces 9, 6796-6803. doi: 10.1021/acsami.6b14176

Teng, X., Tian, M., Zhang, J., Tang, L., and Xin, J. (2018). A tcf-based colorimetric and fluorescent probe for palladium detection in an aqueous solution. Tetrahedron Lett. 59, 2804-2808. doi: 10.1016/j.tetlet.2018.06.016

Tibi, L., Collier, A., Patrick, A. W., Clarke, B. F., and Smith, A. F. (1988). Plasma alkaline phosphatase isoenzymes in diabetes mellitus. Clin. Chim. Acta 177, 147-155. doi: 10.1016/0009-8981(88)90136-2

Wang, G., Zhang, X., Yu, B., and Ren, K. (2015). Gliotoxin potentiates osteoblast differentiation by inhibiting nuclear factor-кb signaling. Ren. Mol. Med. Rep. 12, 877-884. doi: $10.3892 / \mathrm{mmr} .2015 .3524$

Wu, D., Sedgwick, A. C., Gunnlaugsson, T., Akkaya, E. U., Yoon, J., and James, T. D. (2017). Fluorescent chemosensors: the past, present and future. Chem. Soc. Rev. 46, 7105-7123. doi: 10.1039/C7CS00240H

Wymenga, L. F., Boomsma, J. H., Groenier, K., Piers, D. A., and Mensink, H. J. (2001). Routine bone scans in patients with prostate cancer related to serum prostate-specific antigen and alkaline phosphatase. BJU Int. 88, 226-230. doi: 10.1046/j.1464-410x.2001.02275.x

Yang, J., Zheng, L., Wang, Y., Li, W., Zhang, J., Gu, J., et al. (2016). Guanine-rich dna-based peroxidase mimetics for colorimetric assays of alkaline phosphatase. Biosens. Bioelectron. 77, 549-556. doi: 10.1016/j.bios.2015.10.003

Zhang, H., Xiao, P., Wong, Y. T., Shen, W., Chhabra, M., Peltier, R., et al. (2017). Construction of an alkaline phosphatase-specific two-photon probe and its imaging application in living cells and tissues. Biomaterials 140, 220-229. doi: 10.1016/j.biomaterials.2017.06.032

Zhang, H., Xu, C., Liu, J., Li, X., Guo, L., and Li, X. (2015). An enzyme-activatable probe with a self-immolative linker for rapid and sensitive alkaline phosphatase detection and cell imaging through a cascade reaction. Chem. Commun. 51, 7031-7034. doi: 10.1039/C5CC01005E

Zhang, J., Chai, X., He, X. P., Kim, H. J., Yoon, J., and Tian, H. (2019). Fluorogenic probes for disease-relevant enzymes. Chem. Soc. Rev. 48, 683-722. doi: 10.1039/C7CS00907K

Zhang, L., Hou, T., Li, H., and Li, F. (2015). A highly sensitive homogeneous electrochemical assay for alkaline phosphatase activity based on single molecular beacon-initiated $\mathrm{t} 7$ exonuclease-mediated signal amplification. Analyst 140, 4030-4036. doi: 10.1039/C5AN00516G

Zhao, L., Xie, S., Song, X., Wei, J., Zhang, Z., and Li, X. (2017). Ratiometric fluorescent response of electrospun fibrous strips for real-time sensing of alkaline phosphatase in serum. Biosens. Bioelectron. 91, 217-224. doi: 10.1016/j.bios.2016.12.025

Conflict of Interest Statement: The authors declare that the research was conducted in the absence of any commercial or financial relationships that could be construed as a potential conflict of interest.

Copyright $\odot 2019$ Gwynne, Sedgwick, Gardiner, Williams, Kim, Lowe, Maillard, Jenkins, Bull, Sessler, Yoon and James. This is an open-access article distributed under the terms of the Creative Commons Attribution License (CC BY). The use, distribution or reproduction in other forums is permitted, provided the original author(s) and the copyright owner(s) are credited and that the original publication in this journal is cited, in accordance with accepted academic practice. No use, distribution or reproduction is permitted which does not comply with these terms. 